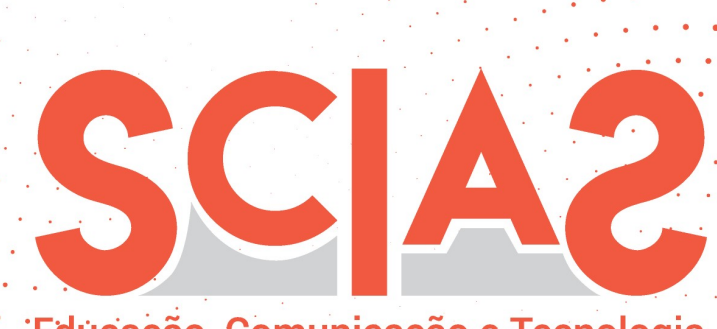

Éduçaçãa, Comunicação e Tecnologia

Edugation, Comunication and Technology

Atribuição BB CY 4.0

\title{
Cantora lúrica em casa, COVID-19 em cena
}

Melina de Lima Peixoto ${ }^{1}$

\section{Resumo}

Neste relato de experiência, apresentamos medidas, alternativas e soluções encontradas para a sustentação do trabalho e da pesquisa acadêmica em casa, no contexto de uma pandemia que impõe distanciamento social e consequente isolamento domiciliar, com a singularidade de tratar-se, o sujeito, de uma cantora lírica profissional e doutoranda em performance musical que lida com a arte direcionada ao público. Durante convivência incessante com os coabitantes de casa, evidenciamos as estruturas que foram levantadas para possibilitar a construção de vídeos musicais e aulas online, entre outras medidas, levando a função do artista/estudante de arte a um novo cenário, considerando, ainda, a interseção com múltiplas tarefas domésticas e relações do ambiente familiar desta autora para com seu cônjuge e sua filha dependente.

\section{Palavras-chave}

Quarentena e trabalho em casa. Pandemia do COVID-19 no Brasil. Cantora lírica em homeoffice. Coral virtual.

Recebido em: 10/07/2020

Aprovado em: 22/12/2020

${ }_{1}$ Doutoranda do Programa de Pós-Graduação em Música da Escola de Música da Universidade Federal de Minas Gerais - UFMG.

E-mail: melina.peixoto@gmail.com 


\section{Lyric singer at home, COVID-19 on the scene}

\section{Abstract}

In this experience report, we present the actions, alternatives and solutions found to support work and academic research at home, in the context of a pandemic that imposes social distance and consequent home isolation, with the singularity of being, the subject, a professional lyrical singer and doctoral student in musical performance that deals with art directed to the audience. During incessant coexistence with cohabitants at home, we highlighted the structures that were built to enable the construction of music videos and online classes, among other measures, bringing the role of the artist/art student to a new scenario, considering, also, the intersection with multiple household chores and relationships of this author's family environment towards spouse and dependent daughter.

\section{Keywords}

Quarantine and work at home. COVID-19 pandemic in Brazil. Lyrical singer in homeoffice. Virtual choir. 


\section{Introdução}

Como membro efetivo no cargo de músico-cantor, funcionária pública estadual, exercemos função no contato diário com colegas no ato do canto lírico, em sala preparada para ensaios de um grupo de até setenta integrantes, com assentos próximos, semelhante aos de uma plateia de teatro. Atuante em espetáculos que abrangem tanto a grandiosidade de uma ópera para uma plateia de mil e setecentos espectadores por récita, quanto curtas apresentações para o público passante na mais importante avenida da cidade e,ao mesmo tempo,cursando o segundo período de doutorado com ênfase em uma das linhas de pesquisa em música do programa de pós-graduação de uma universidade federal, vimo-nos obrigados,assim como uma grande parcela da população do nosso país, pelo bem da saúde de nossa família e do próximo, a recolher-nos em casa em quarentena. Estabeleceu-se,então, a partir do dia 18 de março de 2020, nossa rotina de vinte e quatro horas de proximidade com coabitantes diretos, a saber, cônjuge, também músico e autônomo, e filha de sete anos de idade.

As medidas tomadas em prol do bem-estar de seus funcionários e da comunidade em geral, frequentadora da instituição pública da qual fazemos parte do quadro de artistas, proporcionaram que os quase cento e trinta músicos dos dois corpos artísticos da casa, entre profissionais cantores líricos e instrumentistas, fossem dispensados da continuidade de suas tarefas em seus ambientes de ensaio e performance, os quais favoreciam a propagação da COVID-192, devido à aglomeração essencialmente necessária para a execução do trabalho de grandes grupos musicais.

No cenário relativo ao ambiente da universidade pública que frequentamos, em virtude da preparação dos discentes das disciplinas cursadas durante esse semestre, os conteúdos das aulas presencias da pós-graduação foram rapidamente transferidos para plataformas de ensino à distância, pelas quais pudemos dar continuidade aos mesmos de forma remota. Quase que

${ }^{2}$ Segundo informações retiradas do site do Ministério da Saúde do Governo Federal, "a COVID-19 é uma doença causada pelo coronavírus SARS-CoV-2, que apresenta um quadro clínico que varia de infecções assintomáticas a quadros respiratórios graves.” Disponível em< $<$ https://coronavirus.saude.gov.br/sobre-a-doenca $>$. Acesso em: 23 jun. 2020. 
imediatamente, textos com conteúdos relevantes foram disponibilizados e permitiram que a elaboração de trabalhos em grupo pudesse ser desenvolvida à distância, com o auxílio de aplicativos e programas de mensagens e videoconferência, como Whatsapp, Google Meet, Zoom e Skype. Apesar da facilidade de comunicação que nos foi proporcionada pelo acesso via dispositivos tecnológicos,a implantação de videoaulas com turmas grandes,com horários pré-fixados, apresentou-se com um obstáculo, vez que também havia a necessidade de compartilhar tais dispositivos com os outros moradores de casa, até então transformada em espaço de home-office e de homeschooling.

É, portanto, durante este período atípico que, por ora, vivenciamos a oportunidade de estabelecer rotinas inéditas em nossos lares, com o acréscimo de novas distribuições de tarefas, incluindo a partilha de dispositivos tecnológicos que se tornaram indispensáveis neste contexto. Paralelamente,enquanto cantora lírica no desempenho de nossa função, conjuntamente com um número expressivo de outros artistas, deparamonos,principalmente, com o surgimento de um grande número de soluções originais para o músico confinado que precisa atuar remotamente junto ao público, situação nunca antes vivenciada com tanta efetividade, nem mesmo, sequer, imaginada ou mesmo abordada na educação de nossa geração ou de gerações pretéritas próximas.

Apresentamos, no correr deste relato de experiência, as inusitadas soluções com as quais nos defrontamos para dar continuidade ao trabalho de maneira a manter o contato com o público,o prosseguimento à pesquisa acadêmica concomitantemente à manutenção da saúde do lar de uma forma integral. Ainda, apresentamos nossa perspectiva sobre a busca por medidas esboçadas com o intuito de que,num futuro próximo, retornemos às atividades nos ambientes de trabalho e estudo que se encontram ora vazios, de forma a adotar e manter os cuidados de higiene que a pandemia nos permitiu notar. 


\section{O canto lírico em casa}

À medida que a contaminação pelo COVID-19 se alastrou pelo continente europeu nos primeiros meses do ano de 2020, inúmeras instituições corais e orquestrais,amadoras e profissionais do Brasil e do mundo foram forçadas a avaliar a iminência da suspensão de suas atividades em seus locais de atuação, situação que se confirmou rapidamente.

Com formações que compreendem até15oparticipantes e com atividades de frequência diária a semanal, a depender do nível de profissionalização que cada grupo musical apresenta, a proximidade física entre os membros de tais instituições é inegável e, por tradição e necessidade, vista como obrigatória, sendo que um grupo vocal ou instrumental precisa ouvir-se para atingir uma sonoridade equilibrada e harmônica, respondendo, desta maneira, aos comandos de seu maestro.Além de ensaios rotineiros,tais grupos cumprem sua função primordial de realização de apresentações em ambientes de variados formatos, como teatros fechados, arenas abertas, parques e espaços públicos com a presença da plateia que se aglomera, inevitavelmente, para obter a melhor visão e audição do grupo em sua performance.

Inicialmente, o grupo coral profissional ao qual pertencemos propôs uma discussão entre seus integrantes tendo como tema a propagação da pandemia a aproximar-se de nosso estado e quais alternativas teríamos para continuar nosso trabalho. Ao evidenciar-se o fato de que não haveria uma maneira ideal de continuar o trabalho em condições tradicionais, nossa chefia prontamente dispensou seus corpos artísticos de suas funções presenciais, e passou a elaborar medidas para que seus membros pudessem trabalhar de forma remota. A primeira e, até o presente, a principal forma de contato com o funcionário artista à distância deu-se por meio de mensagens em grupos de contatos já existentes, utilizando-se do aplicativo Whatsapp.Iniciou-se, desta forma, oenvio diário de programação de tarefas, contendo a indicação de obras musicais a serem estudadas e preparadas,com as respectivas cronometragens para melhor proveito do período de ensaio, juntamente com o envio de partituras (nosso principal material de leitura) em formato digital. Sem uma compreensão total 
do processo que teve início, fomos orientados a produzir a partir do estudo remoto, porém sem perspectiva de quando esse material seria apresentado. Foi estabelecido o cumprimento de uma carga horária comum a todos do grupo, tendo como objetivo central o prosseguimento da programação artística, mantida sem alteração até o momento, porém com adaptações que se fizeram necessárias. À medida que as partituras eram preparadas individualmente, foram adicionadas novas obras musicais, de modo que vimos surgir, então, a necessidade da montagem e publicação de um vídeo colaborativo com a participação dos membros do coral e da orquestra. Essa instância surgiu, no momento em questão, em duas frentes, tanto por parte da direção da casa e chefia imediata, haja vista a manutenção do trabalho artístico, função desempenhada por tal instituição pública, quanto pela ânsia dos servidores músicos em se manifestarem. Lembramos que neste contexto referimo-nos a servidores músicos acostumados com uma rotina de ensaios diários e que, por desejo inato, sentiram-se compelidos à tarefa à qual têm se dedicado desde quando se decidiram por essa profissão.

Vimos surgir, desde o início da quarentena, a premência pelo entretenimento e pela arte como um todo por grande parte da população que se isolou em suas casas e que buscou, mais do que nunca, as redes sociais. Notável foi a resposta imediata dos grupos teatrais, musicais, dramáticos e coreográficos que deram início às inúmeras apresentações que tomaram a forma online, em registros ao vivo ou em reprises de apresentações passadas. De maneira simultânea, canais de vídeos pela internet e canais de tecnologia streaming pela televisão passaram a fornecer em meio a seus variados conteúdos que abarcam documentários, filmes e séries, uma programação especificamente voltada para o espectador em quarentena, e vimos emergir com maior vigor a disponibilização de passeios virtuais em bibliotecas, teatros e museus de renome,de forma que os acessos remotos pudessem ser amplificados.

Da parte dos artistas de todos os gêneros, foi sentida a urgência em demonstrar pela internet suas performances, associando-se à necessidade de continuação de seus trabalhos de forma a manter suas fontes de renda que, à época e atualmente, correm risco em sua manutenção. De tal modo, muitos artistas 
alternaram suas aulas presencias para videoaulas e videoconferências, o que possibilitou a muitos deles assegurar o contato com seus alunos e público. Ainda havia aqueles que sendo financiados por empresas patrocinadoras de programas no âmbito artístico-educativo e cultural puderam manter suas atividades contando com este tipo de manutenção. Além disso, o anseio natural por aplausos nos permite o registro de uma licença poética nas linhas cantadas por Milton Nascimento (1942), pois "todo artista tem de ir aonde o povo está"3.

Uma alternativa encontrada e rapidamente difundida por grupos musicais de todo o globo durante a reclusão social imposta pela atual pandemia, foi a montagem de corais e orquestras virtuais que, amplamente divulgados pela internet, firmaram-se com o intuito de manter a função do músico e do contato com o público. Com a divulgação realizada por meio das redes sociais das próprias instituições, e contando principalmente com o compartilhamento dos visualizadores, os integrantes desses grupos musicais acabaram por assumir também a veiculação dos vídeos das instituições às quais pertencem, permitindo, assim, que a arte não parasse em tempos tão sombrios para todas as classes sociais. Vimos surgir e fortalecer, portanto, um novo cargo para o músico profissional de coral e orquestra que agora, além de executante das obras, deve preocupar-se com a divulgação e alcance destas apresentações, função antes gerida exclusivamente pelos responsáveis da área de comunicação e afins.

Foi então que, almejando a montagem de um coral virtual de certa obra musical consagrada, com data específica para divulgação, os cantores do coral em questão, receberam as instruções de como seus vídeos deveriam ser produzidos. Por meio do aplicativo Whatsapp, obtivemos instruções de como os aparelhos de celular equipados com câmeras deveriam ser posicionados, com dados específicos sobre o tipo de resolução de filmagem desejada e, ainda, indicações da maneira com a qual deveríamos nos apresentar nos vídeos: vestimenta e cenário de fundo, que deveria ser o mais neutro possível a fim de atingir um quadro limpo, dando destaque somente ao músico. Uma das principais

3Trecho da canção Nos bailes da vida, de autoria de Milton Nascimento e Fernando Brant, integrante do álbum Caçador de mim, lançado em 1981, pela Ariola. 
dificuldades dos cantores foi o manejo de tantas ferramentas para criação de um vídeocaseiro. Levemos em consideração que para um cantor soar em consonância perfeita com todos os outros membros do coral, o ideal é que ele esteja entre eles, mas, como realizar tal efeito estando cada um em sua residência? Não há uma maneira de colocarmos todos a um mesmo momento online, já que qualquer tentativa nesse sentido implicaria no efeito destrutivo para a música que é o delay 4 obtido na distribuição do material online simultâneo. Levou-se em consideração, ademais, o fato de que, em sua maioria, os cantores vivem agora as vinte e quatro horas do seu dia em suas casas, dividindo o espaço com membros de suas famílias, convivendo com ruídos provenientes da rua e vizinhança, cada um com seus horários distribuídos em rotinas nunca antes experimentadas.

A maneira encontrada para solucionar tal incompatibilidade pela maioria dos grupos musicais foi a criação de uma guia sonora. Juntamente com a partitura enviada digitalmente, constava uma gravação feita pelo pianista acompanhador do grupo, que registrou cada linha melódica, dentre inúmeras que compreendem uma partitura coral, com o acréscimo de um "clique" de contagem, proporcionando aos cantores, já familiarizados com a obra musical em questão, uma maneira de sincronizarem sua parte cantada em um andamento comum a todos do grupo. A preparação desse material ocorreu dentro dos estudos diários de cada cantor lírico, obedecendo a instruções diretas do maestro do grupo, como pronúncia do texto, articulação das palavras, dinâmica musical e dados sobre agógica, termo utilizado no meio musical que diz respeito à alteração de andamentos, expressão e caráter musical, entre outras indicações. Surgiu, então, a necessidade de dois dispositivos a serem utilizados simultaneamente: um para o cantor ouvir a guia sonora para sincronização - com utilização de fones de ouvido, uma vez que na filmagem só deveria constar a voz do cantor - e outro para a filmagem em questão. Em nosso caso, houve ainda a necessidade do apoio de um dispositivo para a leitura da partitura digitalizada, uma vez que, devido ao isolamento social, o material recebido em formato digital não pôde ser impresso. Após o término de cada gravação, os vídeos eram enviados aos membros do grupo que possuíam

4Atraso da entrada de determinado sinal de áudio. 
conhecimento na área de edição, montagem e manipulação, que somando uns aos outros,obtiveram um resultado que se assemelha visualmente a um quadro composto por um conjunto de janelas, formando, por conseguinte, um grande coral virtual.

Além da divulgação dos vídeos em conjunto promovidos pela instituição pública em questão, demos início à tarefa de criação de vídeos caseiros individuais, na qual cada cantor gravou e disponibilizou peças de domínio de seu repertório para publicação em uma campanha criada com tal finalidade. Ora contando com algum som de gravação de piano em acompanhamento ao fundo (playback), ora cantando a cappella5, foram várias as formas com as quais estes vídeos foram desenvolvidos, até atingirmos o domínio de softwares de computador específicos que promovem a junção de áudios gravados separadamente, equalizando-os6, numa etapa final.

Digno de nota são as tão praticadas lives da quarentena, algo tão fenomenal que entre o horário das 19 e 21 horas, no Brasil, em qualquer dia da semana, tornouse difícil conseguir estabilidade nas plataformas que as abrigavam, tais como o Instagram. Tais formas de comunicação também foram uma das estratégias das quais muitos artistas serviram-se para dar continuidade à manutenção da divulgação de suas obras e apresentações, seja por meio de discussões com outras personalidades, ou com a efetiva execução de suas performances ao vivo. Por conseguinte, deu-se início às lives semanais com horário agendado préanunciado entre os integrantes do coral da instituição que tratamos neste relato, com o intuito de tornar o membro cantor lírico profissional uma personalidade não tão distante da realidade do público brasileiro, que muitas vezes considera a música erudita algo unicamente ligado às elites e totalmente fora de seu alcance. Entre os assuntos abordados nestas lives feitas em forma de entrevistas ou "bate-papo" com integrantes do coral, um ponto comum foi o histórico da trajetória de cada membro em questão, o que possibilitou um maior

\footnotetext{
5Segundo o Dicionário Grove de Música (1994),a expressão italiana a cappella (na capela) denomina a música coral cantada sem acompanhamento de instrumentos. ${ }^{6}$ Segundo o Dicionário de termos e expressões da música (DOURADO, 2004), equalização implica na manipulação das frequências de dois ou mais sons, por intermédio de um dispositivo que as reforça ou as atenua.
} 
conhecimento sobre o perfil dos cantores para o público. Desta maneira, notadamente no contexto dos relatos dos cantores, foi evidenciada a origem muitas vezes sem recursos financeiros dos mesmos, mas que, impulsionados pelo contato comcorais que se apresentavam em praças públicas, igrejas e teatros, foi despertado o interesse em fazer parte de um grupo desse gênero.

\section{Um doutorado em meio à quarentena}

Enquanto nos foi imposta uma atuação profissional inusitadamente atarefada, ainda que em meio ao isolamento social de uma quarentena, a universidade pública que abriga nossa pesquisa de doutorado declarou suas aulas presenciais suspensas. Contudo,os trabalhos de escrita e construção da tese prosseguem, pois ocorrem também por meio de encontros virtuais para orientação e pesquisa. Afetadas pelo início da pandemia, as disciplinas do primeiro semestre de 2020 foram transferidas para a forma remota e o contato para orientação da pesquisa segue de forma plena dessa mesma maneira. Trocas de e-mails e mensagens e áudios por Whatsapp entre orientador e orientando tornaram-se diários e altamente relevantes para a continuidade de nossa pesquisa, possibilitando, assim, um maior foco em relação à escrita da tese em curso.

Desta maneira, citamos também a forma com a qual a relação orientadororientando sofreu adaptações diante da atual crise sanitária mundial, pois ao primeiro coube a indicação de ferramentas e recursos para a continuidade da pesquisa e, em nosso caso, a prática da dedicação e da empatia, o que exemplifica o ato de orientar em toda a sua representação. Compreender a situação e condições do orientando é prioridade em uma situação atípica como a que vivencia esta geração e, igualmente, devemos voltar o nosso olhar para o orientador, sujeito que também está experimentando momentos contrastantes em relação à antiga e sólida segurança acadêmica.

\section{Novos planejamentos em casa}

Ao compormos um relato sobre a dinâmica de execução de nosso trabalho e pesquisa acadêmica durante a pandemia do COVID-19, é compreensível que coloquemos o foco sobre os meios de conexão remota, dispositivos e estratégias inusitadas pelos quais podemos criar e manter o trabalho em questão. Embora 
durante esta descrição aprofundemo-nos bastante nesta temática, devemos considerar que o tempo dedicado a tal ocupação é, em verdade, intercalado pelas horas de convívio com a família e de ligeiros momentos de solitude que são, na realidade, o extenso terreno no qual cavamos lacunas de concentração para dar continuidade às tarefas profissionais e estudo.

Com a suspensão do encontro físico de nossas atividades e consequente início de trabalho e estudo remotos, não imaginávamos as medidas nas quais iríamos nos apoiar para o estabelecimento de uma rotina de trabalho e estudos, fato que englobaria também a rotina de cônjuge e filha ainda na segunda infância. Em relação à criança em questão, em pouco tempo fomos acostumando-nos com suas aulas online, desde as do ensino fundamental, até as lições de piano que agora ocorrem ministradas via tablet, de forma que a professora possa enxergar os dedinhos iniciantes de sua pequena aluna.

Para a manutenção de tantas tarefas em conjunto, foi necessário o estabelecimento visual de um quadro de horários rigoroso que inclui aulas online de filha, ao mesmo tempo em que cônjuge, também músico, impedido de ir ao estúdio para a prática de seu instrumento, aloja-se em nosso quarto para sua prática diária. Este também é o principal momento em que nos dedicamos à edição de partituras e desenvolvimento dos textos, tendo a mesa de jantar transformada em escritório durante todo o período da tarde. Relativamente ao citado, alegamos nossa atuação como professora auxiliar do segundo ano do fundamental I, com tarefa especial de orientadora disciplinar durante três horas, controlando a atenção e ansiedade de uma criança de sete anos. Logicamente, ainda dedicamo-nos diariamente aos deveres de casa preparatórios e avaliativos enviados por e-mail pela escola do ensino fundamental e às horas de estudo do canto lírico, intercalados pelo preparo de refeições para todos, tarefas de casa e momentos de descanso e lazer familiar.

Os horários de gravação dos vídeos musicais a serem compartilhados nas redes sociais são arquitetados em períodos diurnos entre o silêncio na obra do apartamento vizinho e após as aulas online já terem sido encerradas. É então, nesses instantes, que recorremos à colaboração da família, para que todos mantenham silêncio absoluto durante tais preciosos minutos que os registros 
em vídeo demandam. Nestes intervalos entre os ruídos da casa, valemo-nos de três dispositivos ao mesmo tempo, com funções de leitura de partitura, audição da guia sonora com fone de ouvido, e gravação dos vídeos.Surge, assim, uma verdadeira produção, considerando-se que o ambiente escolhido deve se tornar um fundo de palco neutro, a câmera do celular posicionada estrategicamente para, enfim, darmos início à performance musical da maneira mais confortável possível, para que seja efetuada no nível profissional com o qual comprometemo-nos a atuar.

\section{Perspectivas possíveis}

Decorridos já quase quatro meses de trabalhos e aulas em conformação remota, a cada dia vemos surgir uma nova ideia, uma nova proposta de ferramenta, uma nova saída para as manifestações artísticas atingirem seu público à distância. No entanto, proporcionalmente à aparição de novas perspectivas para o cenário artístico, expandem igualmente as notícias que dizem respeito ao aumento da propagação do COVID-19, e também com respeito às medidas para o retorno do funcionamento dos locais de trabalho, quando tal ação for possível.

Somos capazes de vislumbrar, no momento atual, que dificilmente será possível retornar aos locais de trabalho da mesma maneira com que vínhamos permanecendo. As medidas sanitárias às quais nos habituamos rapidamente na urgência da situação da expansão do vírus, nos fizeram enxergar os delitos que cometíamos como a não lavagem frequente das mãos, inutilização do álcool gel $70^{\circ} \mathrm{e}$ máscaras, principalmente durante os quadros gripais. Essas medidas poderão ser aplicadas em nosso dia a dia no ambiente de trabalho e universidades, mas o distanciamento social nas salas de ensaio dos grupos musicais deve requerer, assim acreditamos, mais atenção. Em suma, diante das situações presentes, percebemos falhas em nossa educação, que apontam nunca ter sido cogitada a aproximação de uma realidade similar com a qual nos deparamos hoje. O mundo globalizado acreditou-se imune às mazelas de nossos antepassados ao ponto de não julgar necessária a inclusão de dados sobre questões sanitárias como a atual, em nenhuma parte da educação formal de nossa sociedade. Se vivemos em um tempo de maior desenvolvimento científico, aprendemos que isso não nos garante uma segurança plena diante do mundo 
que habitamos e que julgamos, erroneamente, possuir. Assim como o registro curioso exemplificado pela Figura 1 a seguir, que nos mostra a sociedade ocidental diante da explosão da gripe espanhola há cem anos, vimos também surgir uma percepção de fragilidade diante da natureza tantas vezes controlada e ameaçada pelas mãos dos homens:

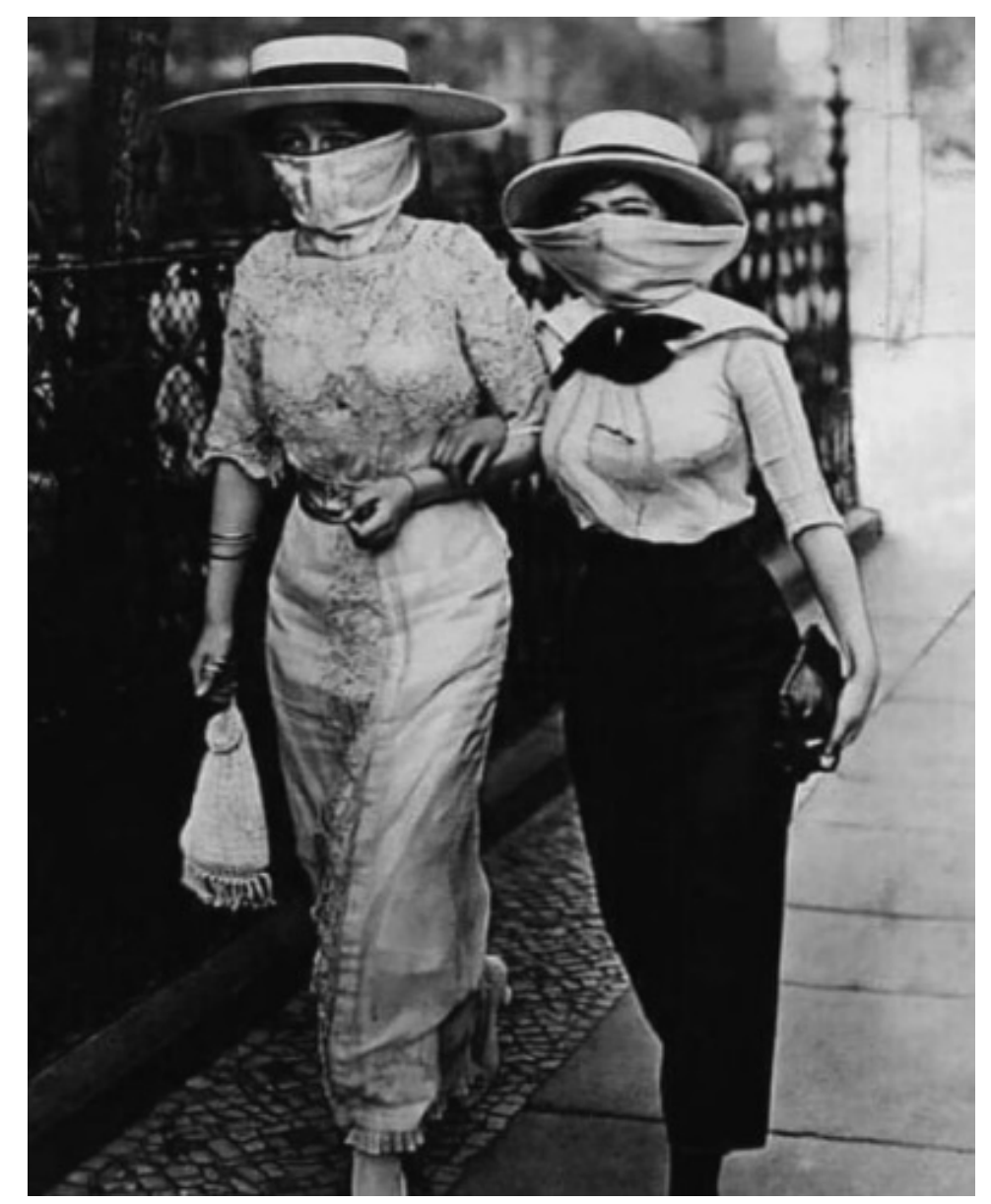

Fig. 1 - Prevenção da gripe espanhola em locais públicos no início do séc. XX77.

Não apresentamos nenhum interesse neste relato de experiência no sentido de propor ou julgar pesquisas realizadas sobre possíveis medidas a serem tomadas para efetivo retorno ao trabalho de grupos musicais corais e orquestrais. Apresentamos apenas parte do que temos vivenciado por meio de leituras e também pela alteração da rotina diária que nos transformou em profissionais reclusos, enclausurados em casa. Possuímos agora apenas uma noção do mundo exterior, proporcionada pela visão de nossas janelas, que nos mostram que aos

\footnotetext{
7 Disponível em: <https://www.cmc.pr.gov.br/ass det.php?not=32251\#\&panel1-1 > Acesso em: 09 jul. 2020.
} 
poucos nos adaptamos às situações atuais tão indesejadas, mas que ao mesmo tempo reforçam nossa fé e esperança por dias melhores, sentimentos presentes em nossa estrutura emocional como recursos para nossa própria sobrevivência.

\section{Reflexões finais}

Vimos que, apesar de toda a incerteza gerada pelo advento de uma pandemia ainda sem perspectiva real de cura ou controle satisfatório, pudemos estabelecer maneiras criativas e inéditas para a manutenção de nossos trabalhos e estudos no contexto de nossos lares, estabelecendo um contato à distância com nosso público e nossos núcleos acadêmicos assim como de nossas relações pessoais. Após medidas de isolamento e cuidados de higiene, nunca anteriormente observados com tanto esmero, deslocamos estruturas de trabalho dos membros da família, escola de nossos filhos, pesquisas acadêmicas, classes de disciplinas individuais ou em conjunto, além de outras atividades complementares, para dentro de nossa rotina doméstica. Para isso, foi necessária a introdução de planejamentos de horários e divisões de espaços físicos e dispositivos tecnológicos, aliados ao cultivo da paciência e ao apoio familiar.

Pudemos notar, durante a criação deste relato de experiência, que as soluções que encontramos para a manutenção de nossos trabalhos e estudos em casa,demandaram com que puséssemos em prática a união de esforços em várias frentes, desde a colaboração entre colegas de trabalho e disciplinas acadêmicas, que nos convidou a adentrar em áreas das quais não tínhamos experiência anterior, até a maior interação com nossos familiares, presentes, agora, em todos os momentos do dia. De tal maneira, a quarentena acabou por revelar-se como uma propiciadora de instantes dos quais nos lembraremos de forma positiva, por mais conflitante que esta realidade nos pareça.

Muito possivelmente, em relação à atividade profissional vocal em conjunto, a alternativa de criação dos corais virtuais e semelhantes será definitivamente integrada aos futuros projetos das instituições com fins artísticos, estabelecendo-se de forma permanente nas programações desses grupos, assim 
como o modelo de aulas online substituirá algumas modalidades que não tenham como exigência a presença in loco dos alunos.

Por fim, podemos dizer que apesar de não vislumbrarmos com muita clareza o momento de retorno às atividades em seus locais tradicionais, o que poderia gerar uma ansiedade negativa, emocionou-nos profundamente assistir ao resultado final dos corais virtuais, resultando na tríade artista-instituiçãopúblico. Há um notável empenho dos cantores e instituição relatados neste estudo para alcançar o público que, igualmente, encontra-se em isolamento social, e que recebe, por meio de tal iniciativa, um pouco do alento que a arte permite com mais intensidade ainda, em um momento cercado de tantas incertezas. Assim, recebemos em troca a gratidão do público que nos assiste e nos alimenta, dessa forma, com o sentimento tão nobre que permite com que sigamos esperançosos em meio à atual crise pandêmica.

\section{Referências}

DOURADO, H. A. Dicionário de termos e expressões da música. São Paulo: Editora 34, 2004.

NASCIMENTO, M.; BRANT, F. Nos bailes da vida. Rio de Janeiro: Ariola,1981. Duração: 4 min.

SADIE, S. Dicionário Grove de música, edição concisa. Rio de Janeiro: Jorge Zahar, 1994. 